\title{
Nonbacterial Thrombotic Endocarditis in Pancreatic Cancer
}

\section{Endocardite trombotica non batterica in associazione con una neoplasia pancreatica}

\author{
Barbara Piovanelli, Riccardo Rovetta, Ivano Bonadei, \\ Enrico Vizzardi, Antonio D’Aloia, Marco Metra
}

\begin{abstract}
Nonbacterial Thrombotic Endocarditis in Pancreatic Cancer. B. Piovanelli, R. Rovetta, I. Bonadei, E. Vizzardi, A. D'Aloia, M. Metra.

Nonbacterial thrombotic endocarditis (NBTE), known as marantic endocarditis, is a phenomenon due to hypercoagulability with a complex pathogenesis. Originally described by Ziegler, the lesions of NBTE were considered to be fibrin thrombi deposited on normal or superficially degenerated cardiac valves [1]. Numerous reports have identified the relationship between NBTE and a variety of different inflammatory states, including chronic diseases like malignancy and autoimmune disease [2, 3]. NBTE is a serious manifestation of prothtombotic state that is characterized by
\end{abstract}

\begin{abstract}
the deposition of thrombi on previously undamaged heart valves in the absence of a bloodstream bacterial infection and by the increased frequency of arterial embolic events in patients with chronic debilitating diseases. Although hypercoagulability is often seen in patients with pancreatic cancer, NBTE has rarely been reported antemortem. We report a case of marantic endocarditis in patient with pancreatic cancer, in which neurological symptoms preceded the diagnosis of pancreatic cancer.
\end{abstract}

Keywords: Nonbacterial thrombotic endocarditis, pancreatic cancer, echocardiography .

Monaldi Arch Chest Dis 2013; 80: 189-192.

Department of Experimental and Applied Medicine, Section of Cardiovascular Diseases, University of Brescia.

Corresponding author: Riccardo Rovetta; Piazzale Spedali civili, 1; I-25100 Brescia; Italy; Tel: +39 030 3995575; Fax: +39 030 3995018; E-mail address: rovetz85@yahoo.it

\section{Background}

Since the seminal observation by Armand Trousseau in $1865^{4}$, numerous studies have confirmed the common association between cancer and thromboembolism. The etiology of the hypercoagulable state in cancer is multifactorial. Contributing factors include procoagulant alterations associated with the malignancy (tissue factor and cancer procoagulant expression by tumor cells, vascular compression by tumor masses) and the host's inflammatory response (monocyte tissue factor expression, increased levels of factor VIII, fibrinogen, and von Willebrand factor). Although venous thromboembolism is the most common manifestation, cancerassociated thrombophilia may also present as a migratory superficial thrombophlebitis (the original syndrome described by Trousseau), arterial thrombosis, disseminated intravascular coagulation (DIC), a thrombotic microangiopathy or nonbacterial thrombotic endocarditis (marantic endocarditis).

\section{Case presentation}

A 48-year-old woman with no significant past medical history, previously asymptomatic, who suddenly showed a lowered level of consciousness, was admitted to department of intensive care unit for stroke. She had no history of tobacco use, con- sumed an occasional alcoholic beverage, and did not have any recent nonsteroidal anti-inflammatory drug use. The computer tomography (CT) of the bran confirmed multiple embolic infarctions throughout both cerebral hemispheres and cerebellum. The distribution of the signal abnormalities was compatible with multiple embolic infarcts. Cardiovascular examination revealed intact carotid and distal pulses without any bruits, regular rhythm with no cardiac murmurs. ECG showed normal sinus rhythm with no ischemic changes. Chest x-ray was normal. Transthoracic and transesophageal echocardiography were significant for multiple vegetations on a trileaflet aortic valve associated with moderate aortic regurgitation (Fig. 1 and Fig 2). During hospitalization, the patient had worsening neurological and repeated CT of brain control with evidence of new ischemic lesions with embolic origin, despite she was treated with iv heparin. Findings were consistent with a new embolization resulting in multiple infarcts. Given the worsening of the clinical condition the patient underwent CT of the abdomen/pelvis (Fig. 3) that showed presence of a mass in the tail of the pancreas. Initial laboratory data were notable for a complete blood count, basic metabolic panel, liver function test, coagulation studies, amylase, lipase, cardiac enzymes, triglycerides, and erythrocyte sedimentation rate: all within normal limits. 


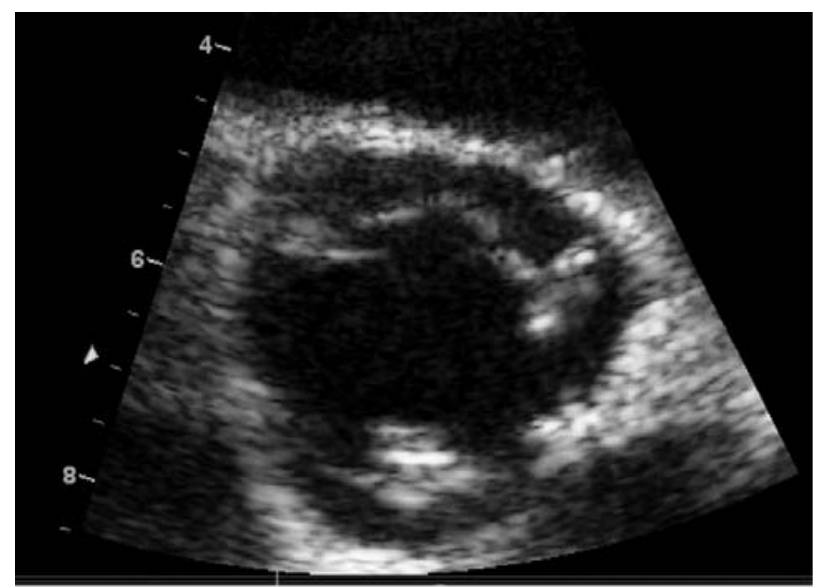

Figure 1. - Short axis view of trileaflet aortic valve with mobile vegetations.

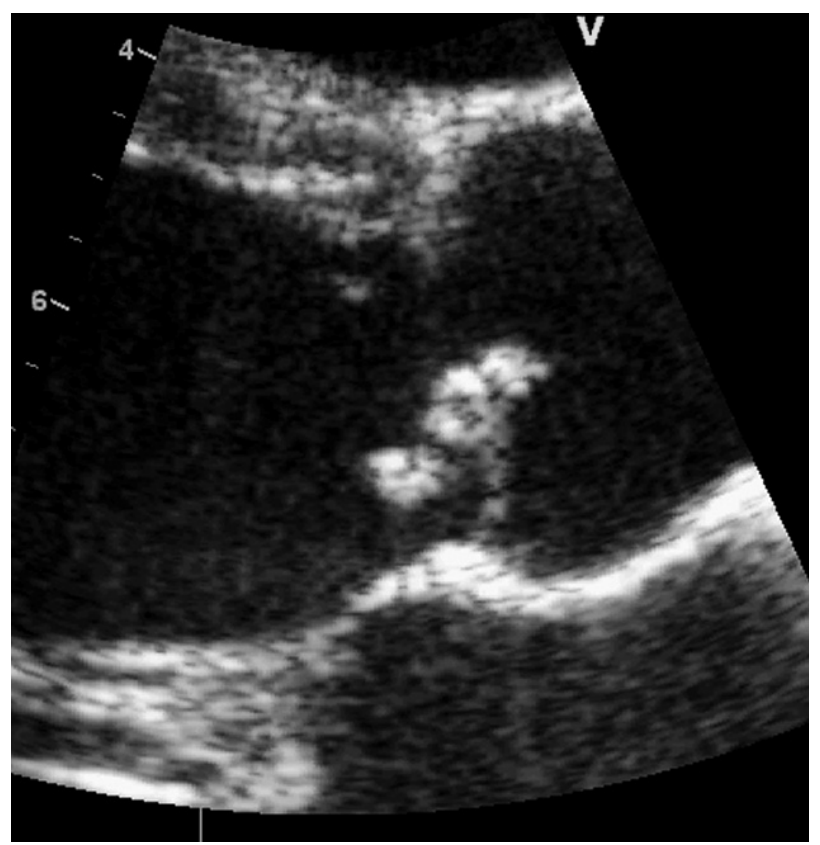

Figure 2. - Long axis view of aortic root showing mobile formation on one leaflet.

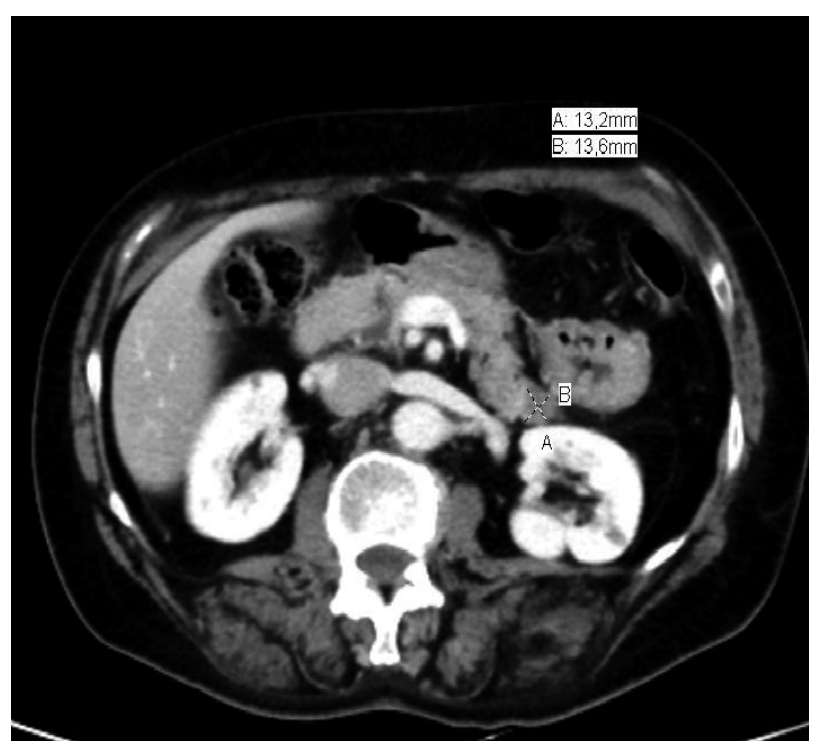

Figure 3. - Abdominal CT showing a mass in the tail of the pancreas.
Workup for bacterial endocarditis was negative, including multiple sterile blood cultures. In suspected endocarditis associated with antiphospholipid syndrome, the patient has performed immunological tests, but they was negative for antinuclear, anticardiolipin, antimitochondrial, and antismooth muscle antibodies. Additional laboratory findings showed CEA of $660 \mathrm{ng} / \mathrm{mL}, \mathrm{CA} 19.9$ of $47 \mathrm{U} / \mathrm{mL}$ and CA 125 level of $721 \mathrm{U} / \mathrm{mL}$. Pancreatic enzymes, erythrocyte sedimentation rate, $\mathrm{C}$-reactive protein, remained within normal limits. The diagnosis of marantic endocarditis was made.

The patient required admission to the intensive care unit for stroke. She was treated with aspirin, beta blocker therapy, and unfractionated heparin. Definitive therapy includes antitumor therapy directed at the underlying malignancy and indefinite anticoagulation with unfractionated or low molecular weight heparin. Vitamin $\mathrm{K}$ antagonists such as warfarin are ineffective and should not be employed in management. In our experience, prompt diagnosis and treatment with heparin and treatment of the patient's pancreatic cancer may prevent catastrophic neurological events and decrease morbidity.

The patient continued on heparin iv and neurological symptoms worsened. Unfortunately, she continued to deteriorate from the pancreatic cancer and died 6 weeks after this hypercoagulable state was diagnosed. This case demonstrates a rare presentation of advanced pancreatic adenocarcinoma. Marantic endocarditis is likely underreported and underdiagnosed. Cancer is associated with a significant hypercoagulable state that increases the risk of thromboembolism fivefold. NBTE is an uncommon but devastating manifestation of malignancy-associated thrombophilia. NBTE should be considered in any cancer patient suffering an episode of arterial thromboembolism. TEE is useful imaging modality in the diagnosis of NBTE. The long-term outcome for most patients with malignancy-associated NBTE is poor, because it is typically associated with disseminated and incurable malignancies. Health care professionals should be alert to the possibility of marantic endocarditis in any patient with cancer, especially pancreatic cancer, who presents with symptoms of neurological dysfunction or an arterial thrombotic event.

\section{Discussion}

NBTE is a phenomenon due to hypercoagulability from an underlying cause. Clinical presentation is most often a sudden neurological deficit. It has been associated with a variety of inflammatory states including malignancy. It is the result of a prothrombotic condition characterized by deposition of sterile fibrin and platelet-rich thrombi on previously undamaged heart valves. Cardiac function is generally unaffected. Associated morbidity and mortality are due to increased frequency of arterial embolic events, specifically in the central nervous system [5]. NBTE is characterized by the presence of an amorphous mixture of platelets and fibrin on a valve leaflet in the absence of inflammation or micro-organisms, or destruction of the underlying cardiac valve [6]. It is most often diagnosed only at postmortem examination because 
the small, friable vegetations frequently embolize, leaving remnants too small to be identified by echocardiography. Vegetations caused by NBTE are found in approximately $1.2 \%$ of patients during autopsy. Although the reported incidence of systemic emboli varies widely, on average $42 \%$ of patients embolize [7]. Arterial embolization most frequently involves the spleen, kidney, brain, and heart, respectively [8]. It is also the major cause of morbidity and mortality in these patients. The most common sites of vegetations are on the mitral and aortic valves along the coaptation line [9]. However, the tricuspid and pulmonary valves as well as bivalvular involvement have been identified $[10,11]$. The great majority of underlying neoplasms associated with NBTE are adenocarcinomas of the pancreas, colon, lung, and prostate. The pathogenesis of NBTE is incompletely understood. The lesions of NBTE are classically found in areas of high flow on valvular leaflets; therefore, blood flow likely contributes to the location if not the initiation of these valvular lesions. Elevated levels of circulating cytokines associated with cancers, such as tumor necrosis factor or interleukin-1 may also result in local tissue damage that instigates vegetation formation. In addition, the interaction between these cells activates the coagulation cascade leading to the generation of thrombin and thrombosis [12]. While NBTE has been reported in every age group, it most commonly affects patients between the fourth and eighth decades of life. No sex predilection has been reported [13]. Therefore, if a diagnosis of endocarditis is made, but the cultures and serology are negative, and there is no response to antibiotic treatment, then NBTE should be strongly considered. Patients with newly acquired murmurs should be evaluated with two-dimensional echocardiography to elucidate the presence of valvular vegetations. The preferred diagnostic test for NBTE is a TEE, which is more sensitive in the detection of valvular vegetations than the transthoracic approach [14]. Although no established treatment strategies exist for tumor related NBTE and DIC, there are limited data supporting the use of anticoagulation in these patients. The most effective anticoagulant appears to be unfractionated heparin, which has been shown to be effective in reducing the incidence of recurrent episodes of thromboembolism $[15,16]$. When delivered in therapeutic doses, both i.v. and s.c. heparin therapy has been effective. In contrast to heparins, vitamin $\mathrm{K}$ antagonists such as warfarin should not be used in patients with malignancy-associated NBTE, as recurrent thromboembolic events while on warfarin are common. A multicenter, randomized trial by Lee et al. [17] demonstrated low-molecular weight heparin was more effective than warfarin in reducing the risk of recurrent thromboembolism in patients with cancer without increasing the risk of bleeding. Although the exact reason for warfarin's inability to control the coagulopathy associated with NBTE is not precisely known, the presence of non-vitamin $\mathrm{K}$ dependent agents that induce the thrombotic coagulopathy has been suggested by some investigators [18].
Anticoagulation must be continued indefinitely in patients suffering from NBTE, because recurrent thromboembolism has occurred in patients following discontinuation of heparin therapy. Although no trial has compared unfractionated heparin with low-molecular weight heparin in patients with tumor associated NBTE, a multicenter double-blind trial published by Sakuragawa et al. [19] demonstrated that low-molecular weight heparin can be used as an alternative to unfractionated heparin in patients with DIC. Although most patients do not require surgery to address NBTE valvular lesions, cardiac surgery is a reasonable intervention in selected circumstances where the risk-benefit balance is favorable.

\section{Riassunto}

L'endocardite trombotica non batterica (NBTE), nota anche come endocardite marantica, è un fenomeno conseguente ad uno stato di ipercoagulabilità con una patogenesi complessa. Originariamente descritta da Ziegler, le lesioni della NBTE sono considerati trombi di fibrina depositata su valvole cardiache normali o degenerate [1]. Numerosi casi hanno identificato il rapporto tra la NBTE e una varietà di diversi stati infiammatori, comprese le malattie croniche come tumori e malattie autoimmuni $[2,3]$. La NBTE è una grave manifestazione di uno stato protrombotico che si caratterizza per la deposizione di trombi sulle valvole cardiache precedentemente intatti in assenza di una infezione batterica nella circolazione sanguigna e da eventi embolici arteriosi nei pazienti con malattie croniche debilitanti. Sebbene lo stato di ipercoagulabilità è spesso visto in pazienti con cancro del pancreas, la NBTE è stato raramente segnalata antemortem. Riportiamo un caso di endocardite marantica in una paziente con neoplasia del pancreas, in cui i sintomi neurologici hanno preceduto la diagnosi di carcinoma pancreatico.

\section{References}

1. Ziegler E. Ueber den Bau und die Entstehung der endocarditis chen Efflorescenzen. Ver Kong Inn Med 1888; 7 : 339-343.

2. Ferrans VJ, Rodriguez ER. Cardiovascular lesions in collagen-vascular diseases. Heart Vessels Suppl 1985; 1: 256-261.

3. Hughson MD, McCarty GA, Sholer CM, et al. Thrombotic cerebral arteriopathy in patients with the antiphospholipid syndrome. Mod Pathol 1993; 6: 644-653.

4. Trousseau A. Clinique Médicale de l'Hôtel-Dieu de Paris. Paris: Ballière; 1865. Phlegmasia alba dolens; p. 654-712

5. El-Shami K, Griffiths E, Streiff M. Nonbacterial thrombotic endocarditis in cancer patients: pathogenesis, diagnosis and treatment. Oncologist 2007; 12: 518-523.

6. Otten HM, Prins MH. Venous thromboembolism and occult malignancy. Thromb Res 2001; 102: V187-V194.

7. Lopez JA, Ross RS, Fishbein MC, et al. Nonbacterial thrombotic endocarditis: A review. Am Heart J 1987; 113: 773-784.

8. Rosen P, Armstrong D: Nonbacterial thrombotic endocarditis in patients with malignant neoplastic diseases. Am J Med 1973; 54: 23-29.

9. Deppisch LM, Fayemi AO: Non-bacterial thrombotic endocarditis. Am Heart J 1976; 92: 723-729. 
10. Biller J, Challa VR, Toole JF, et al. Nonbacterial thrombotic endocarditis. A neurologic perspective of clinicopathologic correlations of 99 patients. Arch Neurol 1982; 39: 95-98.

11. Reagan TJ, Okazaki H. The thrombotic syndrome associated with carcinoma. A clinical and neuropathologic study. Arch Neurol 1974; 31: 390-395.

12. Bick RL: Cancer-associated thrombosis. N Engl J Med 349: 109-111, 2003

13. Lopez JA, Ross RS, Fishbein MC, et al. Nonbacterial thrombotic endocarditis: A review. Am Heart J 1987; 113: 773-784.

14. Dutta T, Karas MG, Segal AZ, Kizer JR. Yield of transesophageal echocardiography for nonbacterial thrombotic endocarditis and other cardiac sources of embolism in cancer patients with cerebral ischemia. Am J Cardiol 2006; 97: 894-898.

15. Rogers LR, Cho ES, Kempin S, et al. Cerebral infarction from non-bacterial thrombotic endocarditis: Clinical and pathological study including the effects of anticoagulation. Am J Med 1987; 83: 746-756.

16. Sack GH Jr., Levin J, Bell WR. Trousseau's syndrome and other manifestations of chronic disseminated coagulopathy in patients with neoplasms: Clinical, pathophysiologic, and therapeutic features. Medicine (Baltimore) 1977; 56: 1-37.

17. Lee AYY, Levine MN, Baker RI, et al: Low molecularweight heparin versus a coumarin for the prevention of recurrent venous thromboembolism in patients with cancer. N Engl J Med 2003; 349: 146-153.

18. WR, Starksen NF, Tong S, et al. Trousseau's syndrome. Devastating coagulopathy in the absence of heparin. Am J Med 1985; 79: 423-430.

19. Sakuragawa N, Hasegawa H, Maki M, et al: Clinical evaluation of low-molecular weight heparin (FR-860) on disseminated intravascular coagulation (DIC) - a multicenter co-operative double-blind trial in comparison with heparin. Thromb Res 1993; 72: 475-500. 